\title{
Subjetividade e trabalho: \\ algumas contribuições conceituais de Michel Foucault
}

Tatiana Ramminger ${ }^{1}$

Henrique Caetano Nardi²

RAMMINGER, T.; NARDI, H.C. Subjectivity and work: some conceptual contributions from Michel Foucault. Interface - Comunic., Saúde, Educ., v.12, n.25, p.339-46, abr./jun. 2008.

This article intends to contribute towards the field of studies on the relationships between health and work, and particularly regarding discussions on the relationship between subjectivity and work. Subjectivity is a concept widely used in psychology, even though there is little consensus about its meaning. This article seeks to discuss the concept of subjectivity in Michel Foucault's work, and suggests that this may be a strategic concept, in that it makes it possible to think in terms of the indissociability between individual and collective, interior and exterior, inside and outside, and individual and society. Through this, the dichotomies traditionally present in the field of psychology and in studies on the relationship between work and health are broken.

Key words: Work. Social psychology. Governamentality.
Este artigo pretende contribuir para o campo de estudos das relações entre saúde e trabalho, particularmente para a discussão da relação entre subjetividade e trabalho. Subjetividade é um conceito amplamente utilizado em psicologia, mas nem por isso há um consenso a respeito de seu significado. Busca-se discutir o conceito de subjetividade em Michel Foucault, sugerindo que este pode ser um conceito estratégico, na medida em que nos permite pensar a partir da indissociabilidade entre individual e coletivo, interior e exterior, dentro e fora, indivíduo e sociedade, rompendo com as dicotomias que tradicionalmente marcaram os campos da psicologia e dos estudos sobre a relação saúde e trabalho.

Palavras-chave: Trabalho. Psicologia social. Governamentalidade. 
No curso de sua história, o homem não cessou de se construir a si mesmo, ou seja, de trasladar continuamente o nível de sua subjetividade, de se constituir numa série infinita e múltipla de subjetividades diferentes que nunca alcançam um final nem nos colocam na presença de algo que pudesse ser o homem.

(Foucault, 2002, p.403)

Um mesmo conceito pode ter diversas definições, dependendo da disciplina, do contexto, do uso, do autor, da interpretação. Observamos que, por vezes, conceitos amplamente utilizados, cuja definição parece evidente e consensual, são justamente aqueles que se prestam às maiores confusões e distorções. Acabam por ser utilizados para "qualquer coisa", perdendo em precisão e em força.

Um exemplo na psicologia e, mais especificamente, na psicologia social, são as discussões que giram em torno da "subjetividade", e suas derivações: subjetivação, sujeito, modos e processos de subjetivação, etc. São sinônimos? Há uma clara distinção entre eles? Opõem-se a outros conceitos? Como nos ajudam a pensar (diferente)?

A subjetividade é um conceito estratégico para a psicologia social (Nardi, 2006) na medida em que permite pensar com base na indissociabilidade entre individual e coletivo, interior e exterior, dentro e fora, indivíduo e sociedade, rompendo com as dicotomias que tradicionalmente marcaram essa disciplina. A raiz não só da palavra, mas, sobretudo, do conceito "subjetividade", remete à experiência de sermos sujeitos, no duplo sentido da palavra (aquele que é submetido e aquele que realiza a ação), em cada tempo e em cada contexto.

Mas o que é o sujeito? A trajetória moderna e contemporânea do pensamento ocidental foi marcada por esta pergunta. Alguns filósofos, sobretudo a partir de Descartes, construíram a idéia do sujeito como indivíduo, como substância que existe a priori, com uma essência ou intenção a ser descoberta. O fenômeno do indivíduo como dominância de expressão da subjetividade está diretamente ligado ao desenvolvimento do Estado Moderno, a partir do século XVI, que estabeleceu uma nova forma política de poder, combinando astuciosamente as técnicas de individualização e os procedimentos de totalização (Foucault, 1999a).

Ao contrário das formas de governo no Feudalismo e no Absolutismo, o Estado Moderno não se coloca como entidade transcendente, e o governante - ao contrário do príncipe de Maquiavel - não está acima dos demais mortais, em uma hierarquia marcada pela lei e sustentada pela ordem divina (Foucault, 1999a). Os indivíduos podem ser integrados desde que se submetam a um conjunto de modelos e normas bem específicos (Foucault, 1995). É a instauração do Estado Liberal que coloca o indivíduo, a família e a população como alvos da arte de governar. É a lei dos homens, construída no lluminismo, que passa a gerir a nova ordem. A racionalidade que se gesta é aquela da defesa do território a partir do mito da nação, de uma promessa de felicidade para todos (o bem comum) e de uma utopia de futuro glorioso. Esses elementos, ao mesmo tempo em que possibilitam e justificam o governo dos vivos, mantêm o direito do Estado e o dever do cidadão de lutar pela defesa das sociedades nacionais.

Foucault (2004a) lembra que, depois da $2^{a}$ Guerra Mundial, diante dos massacres e do despotismo promovidos pelos Estados, surgiu a idéia de que cabia ao sujeito dar um sentido às suas escolhas existenciais e que estas deveriam libertar-se do modelo de "homem" da racionalidade moderna, marcado pela disciplina. O existencialismo, encabeçado por Sartre, bem como a fenomenologia, retomada por pensadores como Husserl e Merleau-Ponty, dominavam a cena européia, quando Foucault lançou o livro "As Palavras e as Coisas", com a seguinte polêmica:

Uma coisa em todo caso é certa: é que o homem não é o mais velho problema nem o mais constante que se tenha colocado ao saber humano. Tomando uma cronologia relativamente curta e um recorte geográfico restrito - a cultura européia desde o século XVI - pode-se estar seguro de que o homem é aí uma invenção recente. Não foi em torno dele e de seus segredos que, por muito tempo, obscuramente, o saber rondou [...]. O homem é uma invenção cuja recente data a arqueologia de nosso pensamento mostra facilmente. E talvez o fim próximo. (Foucault, 2002, p.404) 
"As palavras e as coisas" é, sobretudo, um gesto de recusa, de rejeição, das teorias a priori do sujeito (Eribon, 1990). É por isso que uma crítica apressada considerou incoerente o "retorno ao sujeito" das últimas obras do filósofo. Fica muito claro, no entanto, que não é um retorno ao mesmo sujeito. Foucault continuou recusando uma forma universal do sujeito, considerando que o sujeito não é uma substância, mas forma e experiência. Seu problema "não era definir o momento a partir do qual alguma coisa como o sujeito apareceria, mas sim o conjunto dos processos pelos quais o sujeito existe com seus diferentes problemas e obstáculos" (Foucault, 2004b, p.261).

Foucault (2004a) identifica duas vias que poderiam conduzi-lo para além da filosofia do sujeito. A primeira era a teoria do saber objetivo, a análise dos sistemas de significação (semiologia). A segunda era a via aberta por uma certa escola da lingüística (Barthes), da psicanálise (Lacan) e da antropologia (Lévi-Strauss), que se agruparam sob a definição de "estruturalismo". Foucault, no entanto, procurou um outro caminho: "Tentei sair da filosofia do sujeito fazendo uma genealogia do sujeito moderno, que abordo como uma realidade histórica e cultural: ou seja, como alguma coisa capaz de se transformar" (Foucault, 2004a, p.94).

O fio condutor do trabalho de Foucault, segundo o próprio, foi a relação entre sujeito e verdade, estudando os modos pelos quais o sujeito pôde ser inserido, como objeto, nos jogos de verdade, ou ainda, como o sujeito tornou-se objeto de conhecimento (objetivação do sujeito).

Uma história que não deveria ser aquela do que poderia existir de verdadeiro nos conhecimentos, mas sim uma análise dos 'jogos de verdade', dos jogos do verdadeiro e do falso através dos quais o ser se constitui historicamente como experiência, ou seja, como podendo e devendo ser pensado. (Foucault, 2004b, p.195)

Ele debruçou-se sobre a objetivação do sujeito no discurso científico, na formação das ciências humanas, como ser que fala (filologia), vive (biologia) e trabalha (economia). Analisou a objetivação do sujeito nas práticas divisoras, ou seja, como o sujeito pôde aparecer do outro lado de uma divisão normativa e, assim, se tornar objeto de conhecimento, na qualidade de louco, doente ou delinqüente. Finalmente, estudou a constituição do sujeito como objeto para ele próprio: a formação dos procedimentos pelos quais o sujeito é levado a se observar, se analisar, se decifrar e se reconhecer como campo de saber possível. Em resumo: como nos constituímos como sujeitos de nosso saber; como sujeitos que ocupam diferentes posições nas relações de poder; e como sujeitos morais em nossas ações (Foucault, 2004a, 2004c, 2004d, 1995).

Interessa-nos, nessa reflexão, sobretudo, a última parte da obra desse autor, quando pretende compreender como "o si" se constitui, elaborando como que uma história da subjetividade, "se entendermos essa palavra como a maneira pela qual o sujeito faz a experiência de si mesmo em um jogo de verdade, no qual ele se relaciona consigo mesmo" (Foucault, 2004d, p.236).

A relação consigo nos remete àquilo que Foucault identificou como as "técnicas de si" para os gregos, que permitem, a cada um, realizar por si mesmo "um certo número de operações em seu corpo, em sua alma, em seus pensamentos, em suas condutas, de modo a produzir uma modificação, uma transformação e a atingir um certo estado de perfeição, de felicidade, de pureza, de poder sobrenatural" (Foucault, 2004a, p.95). As técnicas de si somam-se aos três tipos principais de técnicas analisados por Habermas (citado por Foucault, 2004a): as técnicas que permitem produzir, transformar, manipular as coisas (técnicas de produção); as técnicas que permitem utilizar sistemas de signos (técnicas de significação ou de comunicação); e as técnicas que permitem determinar a conduta dos indivíduos (técnicas de dominação). E, assim, Foucault (2004a, p.95) conclui: "Se quisermos analisar a genealogia do sujeito na civilização ocidental, é preciso considerar não apenas as técnicas de dominação, mas também as técnicas de si".

Da mesma forma, o trabalho não deve ser analisado apenas em relação às técnicas de produção e dominação, mas considerando a maneira como os sujeitos vivenciam e dão sentido às suas experiências de trabalho. Estas também variam conforme o contexto social, histórico e econômico, apontando para diferentes processos de produção de subjetividade, diferentes sujeitos trabalhadores. A relação com o trabalho certamente é vivida de forma distinta entre o cidadão e o escravo na Grécia, o senhor e o servo 
na Idade Média, ou entre o operário da indústria fordista e o jovem analista de sistemas nas atuais empresas (Nardi, 2006).

Ampliado o entendimento do conceito de subjetividade, debrucemo-nos novamente sobre o sujeito, ou melhor, sobre a complexa construção de uma lógica de pensamento, sobre por que nos reconhecemos como uma unidade separada do mundo externo. Pelo menos essa é a experiência moderna da subjetividade que é vivida virada para si, na perspectiva da primeira pessoa (Ortega, 1999) e que acaba por influenciar, também, a relação contemporânea com o trabalho.

Butler (1997) é uma das autoras que se interessou pelo tema, estudando como nos constituímos como sujeitos, a partir da incorporação de normas sociais, tentando estabelecer um diálogo conceitual entre Foucault e Freud. Para ela, a idéia de Foucault de que o sujeito é formado em sua sujeição, a partir das relações de poder, encontra ressonância no processo descrito por Freud em relação à formação das instâncias psíquicas. Em ambos, o sujeito carrega o paradoxo da submissão a outros por meio do controle e dependência (sujeição), ao mesmo tempo em que esse assujeitamento permite a construção de uma identidade, pela consciência ou conhecimento de si mesmo. Submeter-se é, portanto, condição primeira de possibilidade da existência.

No entanto, esse assujeitamento, em Foucault, também é paradoxal, pois que nos aprisiona a normas mas traz, em si mesmo, as possibilidades de resistência. Isso porque, para ele, o poder não é uma "forma", mas um conjunto de relações, que além de não ter efeito apenas repressivo, mas também produtivo e constitutivo, sempre está acompanhado da resistência. Foucault (1999b) afirmava que onde não existe possibilidade de resistência não há relações de poder, mas um estado de dominação. Seu conceito de resistência também é diferente daquele da psicanálise, onde não é possível mudar a "Lei", o ideal normativo, o modelo. Para Foucault, o Imaginário, ou a consciência, não é produto apenas das normas, mas também da resistência, pois ninguém consegue adaptar-se completamente a um modelo, sempre há algo que escapa, que resiste. Para as vertentes conservadoras da psicanálise, a Lei está dada e tem a possibilidade de se atualizar. Para Foucault, a Lei está em permanente construção, por pressupor uma relação. Quando a Lei retorna e incide sobre o sujeito, ela já retorna de outro jeito, sob efeito de um deslizamento produzido pela transformação do tempo e das condições de sua instalação primeira. Não seria uma atualização, mas uma reinstalação da Lei. O discurso não constitui um sujeito unilateralmente, mas simultaneamente e, por isso, a mesma norma que aprisiona traz em si a possibilidade de resistir a ela e transformá-la.

Essas considerações são importantes para pensar o trabalho, pois ali onde parece não existir nada, além de regra e disciplina, é justamente onde pode estar o maior potencial de resistência. Estudar a relação entre subjetividade e trabalho é estar atento, portanto, não apenas às formas de assujeitamento, mas também às transgressões e às possibilidades de invenção de outros modos de lidar com as normas, quiçá transformando-as.

A maneira de relacionar-se com as regras, estabelecidas em cada período histórico, definem os modos e processos de subjetivação. O modo de subjetivação diz respeito à forma predominante dessa relação, ao passo que o processo de subjetivação é a maneira particular como cada um estabelece essa relação em sua vida (Nardi, 2006). Assim, quando falamos dos modos de subjetivação de uma categoria de trabalhadores, estamos nos referindo ao modo predominante e a como os trabalhadores relacionam-se com o regime de verdades que atravessa seu trabalho (os discursos da qualidade total, da eficiência, do "vestir a camiseta"), vendo-se ligados ao cumprimento de determinadas regras estabelecidas por esse discurso que, ao mesmo tempo, permitem seu reconhecimento enquanto trabalhador. Já o processo de subjetivação seria como cada trabalhador vivencia essa relação em sua trajetória particular.

Entendendo a relação que Foucault estabelece entre poder, saber e subjetivação, podemos avançar em sua problematização do modo de governo contemporâneo e de como este produz sujeitos, práticas e saberes no campo do trabalho. Embora sempre tenha feito um esforço para demonstrar que Estado e poder não são sinônimos (já que o poder, em sua condição relacional, não pode ter localização específica), Foucault não deixou de lado a questão do Estado.

Ao final da década de 1970, o filósofo dedicou-se a fazer uma genealogia do Estado Moderno, traçando três principais momentos. Primeiro, o Estado de justiça, definido a partir do território, do tipo 
feudal e ancorado em uma sociedade da lei. Posteriormente, um Estado administrativo (séculos XV e $X V I$ ), que diz respeito a uma territorialidade do tipo fronteiriça e a uma sociedade do regulamento e da disciplina. Finalmente, o Estado de governo, que não mais se define pela noção de território ocupado, mas de população. A noção de governo é entendida de forma ampla, incluindo técnicas e procedimentos destinados a dirigir a conduta dos indivíduos, aqui especificamente por meio de uma ação estatal (Foucault, 1999a, 1997). É assim que uma habilidade que dependia exclusivamente das virtudes do "príncipe", passou a integrar uma "arte de governar", para finalmente especializar-se em uma técnica: a governamentalidade, "uma forma bastante específica e complexa de poder que tem como alvo a população, por forma principal de saber a economia política e, por instrumentos técnicos essenciais, os dispositivos de segurança" (Foucault, 1999a, p.291).

Este momento marca, ainda, a crítica da função do Estado realizada pelo liberalismo. Liberalismo, entendido aqui, como nos lembra Foucault, não como uma teoria, ideologia, doutrina ou política, mas, sobretudo, como uma reflexão crítica sobre a prática governamental (Foucault, 1997). O problema até então era discutir como reforçar o exercício do Estado, que ainda era omisso em inúmeras áreas, sendo que só uma governamentalidade crescente poderia regular o desenvolvimento de uma sociedade harmônica. Em suma, se há problemas, é porque se governa muito pouco. O liberalismo, por sua vez, é atravessado pelo princípio: "governa-se sempre demais", ou ainda, "por que seria preciso governar?" O liberalismo inverte a finalidade do Estado, que não deve ser voltado para si mesmo, ou seja, para a maximização de seu controle, mas para a sociedade: "A reflexão liberal não parte da existência do Estado, encontrando no governo um meio de atingir essa finalidade que ele seria para si mesmo, mas da sociedade que vem a estar em uma relação complexa de exterioridade e interioridade em relação ao Estado" (Foucault, 1997, p.91).

Nesse processo, Foucault vai distinguir, ainda, o liberalismo pós-guerra alemão, e o liberalismo americano, da escola de Chicago. Para o primeiro, as disfunções e problemas da sociedade capitalista não são inatos ao capitalismo, mas fruto da má intervenção estatal. O Estado, neste sentido, não tem uma função negativa ou compensatória (limitando-se à transferência e redistribuição de renda, por exemplo), mas positiva, já que é a base para a criação das condições históricas e sociais do mercado. É a proposta de construir uma economia, não sob uma base naturalista, mas institucional (Lemke, 2001). Já na tradição americana, a matriz econômica generaliza-se para todas as áreas, em dois principais movimentos: áreas não econômicas são investigadas valendo-se de categorias econômicas, ao mesmo tempo em que há uma forte crítica das práticas governamentais, também com base em conceitos do mercado. As relações sociais e comportamentais podem ser explicadas utilizando-se a economia como critério, enquanto a noção de racionalidade do Estado é substituída pela idéia de que o Estado não define ou monitora o livre mercado, e sim o mercado que é o princípio organizador e regulador do Estado (Lemke, 2001). Enquanto o modelo alemão considera que a regulação dos preços pelo mercado é, em si, tão frágil que deve ser sustentada por uma política interna e vigilante de intervenções sociais, "o neoliberalismo americano estende a racionalidade do mercado, os esquemas de análise que ela propõe e os critérios de decisão que sugere, a domínios não prioritariamente econômicos" (Foucault, 1997, p.96).

Um exemplo citado por Lemke (2001) é a "teoria do capital humano", um tipo especial de "capital", visto que não pode ser separado da pessoa que o possui, resultado da predisposição genética somada ao investimento pessoal de cada um. O salário dos trabalhadores, nesse modelo, parece não mais ser dependente da política econômica de cada organização, mas resultado das decisões e investimentos em si mesmo, de cada trabalhador. Assim, o neoliberalismo integra a racionalidade do governo à ação racional dos indivíduos, em uma clara demonstração da polaridade entre subjetividade e poder, e de como as políticas de governo se estendem às formas de auto-regulação subjetiva: tecnologia de governo e técnicas de si.

Certos estudos sobre a relação entre Estado e sociedade revelam que o neoliberalismo não é a redução do Estado ou sua limitação a funções básicas, ao contrário, no modelo neoliberal, o Estado não só retém sua função tradicional, como incorpora novas tarefas e funções. Desenvolve indiretamente técnicas de controle dos indivíduos sem, no entanto, precisar responsabilizar-se por eles. A estratégia de formar sujeitos responsáveis por si mesmos (e também pelos coletivos, famílias, associações etc), transfere a responsabilidade pelos riscos sociais, antes atribuída ao Estado, para a esfera das escolhas 
individuais. A aparente "retirada" do Estado também é uma técnica de governo. A competência regulatória do Estado é, paulatinamente, substituída pelo apelo à responsabilidade individual e ao autocuidado. A estratégia neoliberal é, portanto, suplementar os antigos mecanismos regulatórios e disciplinares, com o desenvolvimento de técnicas de auto-regulação (Lemke, 2001).

O trabalhador agora é autônomo, flexível, enxuto (mas não só ele, também as instituições e o Estado!), assumindo integralmente a responsabilidade por sua atividade, bem como por suas possíveis falhas. As principais revistas e telejornais brasileiros estão recheados de exemplos que parecem enunciar de diferentes maneiras: "o problema não é o mercado de trabalho, é você!" Os cursos de aperfeiçoamento, ao invés de apresentar um "custo", convidam a um "investimento". Livros de autoajuda, sempre na lista dos mais vendidos, prometem resolver os problemas sociais pela prometida revolução - não contra o capitalismo, patriarcado ou racismo - mas contra a maneira equivocada de se governar a si mesmo (Lemke, 2001). Recentemente, por exemplo, a revista Veja publicou matéria com a seguinte manchete: "Gordura faz mal para o bolso: pesquisas mostram que as pessoas gordas têm renda menor que a das magras", citando estudos americanos da Universidade de Ohio e de Nova York que relacionam a perda de peso ao aumento da renda, e vice-versa (Revista Veja, 28 de setembro de 2005, p.102). Nesse modelo neoliberal de racionalidade de governo, as bordas entre público e privado são redesenhadas, e o foco de uma possível intervenção não é mais da ordem política e social, mas individual e subjetiva, em uma precária e forjada harmonia entre as políticas de estado e o estado subjetivo, onde o bem-estar social depende do bem-estar individual (Lemke, 2001).

Para entender o sujeito contemporâneo e, conseqüentemente, seus modos de trabalhar, deve levarse em conta não apenas as técnicas de dominação, mas também as técnicas de si, ou melhor, a interação entre esses dois tipos de técnica. O ponto onde as técnicas de si são integradas nas estruturas de coerção e dominação, onde a tecnologia de dominação dos indivíduos transforma-se em outro recurso desse processo por atos dos indivíduos sobre si mesmos, em uma técnica de governo específica, denominada por Foucault de "governamentalidade". Governar pessoas não é um jeito de forçá-las a fazer o que o governo quer que façam; mas um versátil equilíbrio, com complementaridade e conflito, entre as técnicas que asseguram a coerção e os processos, por meio dos quais, o si é construído ou modificado por si mesmo (Foucault citado por Lemke, 2001).

Lemke (2001) nos lembra que o conceito de governamentalidade é particularmente potente, pois ele permite demonstrar que o neoliberalismo é um projeto político que criou uma sociedade sugerindo que ela já existia. A captura subjetiva aí construída foi problematizada por Foucault no final de sua obra, quando ele, pela via da obliqüidade histórica (Gros, 2002), busca nos mostrar como o sujeito grego se constituía de forma distinta, tanto no que se refere aos cuidados de si como no estatuto da relação com a verdade. Essa diferença nos possibilita pensar que podemos nos constituir de múltiplas formas $\mathrm{e}$ inventar novas estilísticas da existência, não restritas ao julgamento permanente do tribunal do mercado. Mostrar que somos mais livres do que pensamos, como ele mesmo afirma, quando busca dar um sentido a sua obra (Foucault, 1994). 


\section{Referências}

BUTLER, J. The psychic life of power: theories in subjection. California: Stanford University Press, 1997.

ERIBON, D. Michel Foucault: 1926-1984. São Paulo: Companhia das Letras, 1990.

FOUCAULT, M. Sexualidade e solidão. In: MOTTA, M.B. (Org.). Ética, sexualidade, política. Rio de Janeiro: Forense Universitária, 2004a. p.92-103. (Ditos e escritos, 5)

O uso dos prazeres e as técnicas de si. In: MOTTA, M.B. (Org.). Ética, sexualidade, política. Rio de Janeiro: Forense Universitária, 2004b. p.192-217. (Ditos e escritos, 5)

O retorno da moral. In: MOTTA, M.B. (Org.). Ética, sexualidade, política. Rio de Janeiro: Forense Universitária, 2004c. p.252-63. (Ditos e escritos, 5)

Ética, sexualidade, política. In: MOTTA, M.B. (Org.). Ética, sexualidade, política.Rio de Janeiro: Forense Universitária, 2004d. p.234-9. (Ditos e escritos, 5)

As palavras e as coisas. São Paulo: Martins Fontes, 2002.

A governamentalidade. In: MACHADO, R. (Org.). Microfísica do poder. Rio de Janeiro: Graal, 1999a. p.277-93.

La ética del cuidado de sí como práctica de la libertad. In: Estética, ética e hermenêutica: obras esenciales. Barcelona: Paidós, 1999b. v.3. p.393-415. 1997. Resumo dos cursos do Collège de France (1970-1982). Rio de Janeiro: Zahar,

O sujeito e o poder. In: DREYFUS, H.; RABINOW, P. (Orgs.). Michel Foucault: uma trajetória filosófica - para além do estruturalismo e da hermenêutica. Rio de Janeiro: Forense Universitária, 1995. p.231-49.

Verité, pouvoir et soi. In: DEFERT, D.; EWALD, F. (Orgs.). Dits et ecrits. Paris: Gallimard, 1994. p.777-83.

GROS, F. Foucault, le courage de la verité. Paris: PUF, 2002.

LEMKE, T. The birth of bio-politics: Michel Foucault's lecture at the Collège de France on neo-liberal governmentality. Econ. Soc., v.30, n.2, p.190-207, 2001.

NARDI, H.C. Ética, trabalho e subjetividade: trajetórias de vida no contexto do capitalismo contemporâneo. Porto Alegre: UFRGS, 2006.

ORTEGA, F. Amizade e estética da existência em Foucault. Rio de Janeiro: Graal, 1999. 
RAMMINGER, T.; NARDI, H.C. Subjetividad y trabajo: algunas contribuciones conceptuales de Michel Foucault. Interface - Comunic., Saúde, Educ., v.12, n.25, p.339-46, abr./jun. 2008.

Este artículo pretende contribuir para el campo de estudios de las relaciones entre salud y trabajo, particularmente para la discusión de la relación entre subjetividad y trabajo. Subjetividad es un concepto ampliamente utilizado en psicología, aunque pese a ello no hay consenso respecto a su significado. Se busca discutir el concepto de subjetividad en Michel Foucault, sugiriendo que este puede ser un concepto estratégico, en la medida en que nos permite pensar a partir del hecho de que no se puede disociar lo individual de lo colectivo, interior y exterior, dentro y fuera, individuo y sociedad, rompiendo las dicotomías que tradicionalmente marcaron los campos de la psicología y de los estudios sobre la relación salud y trabajo.

Palabras clave: Trabajo. Psicología social. Governamentalidad.

Recebido em 28/03/07. Aprovado em 14/02/08. 